\title{
A Teoria da Justiça de Rawls Como Uma Teoria de Direitos Fundamentais
}

\section{Feliciano de Carvalho}

Doutorando em Direito Constitucional pela Universidade de Fortaleza - Unifor; mestre em Direito Constitucional pela Universidade de Fortaleza - Unifor; especialista em Direito Empresarial; professor de Direito Constitucional; Defensor Público Federal de 1a Categoria. $f$ elicianodecarvalho@yahoo.com.br

\section{Resumo}

Este artigo fará uma análise sobre a teoria da Justiça de Rawls como uma teoria dos direitos fundamentais. 0 objetivo é demonstrar que a noção dos princípios básicos de Justiça e de bens primários trata-se de uma forma de proteção dos direitos fundamentais, especialmente do direito à liberdade e à igualdade. A metodologia de pesquisa é bibliográfica. Ao final, conclui-se que os direitos fundamentais são 0 critério de Justiça de Rawls e, por consequência, consistem no fundamento do próprio texto constitucional, a servir, também, como justificativa extrapositiva da norma hipotética fundamental. A Justiça seria o respeito aos direitos fundamentais básicos

Palavras-chave: Rawls. Justiça. Direitos fundamentais.

\section{The Rawl's Justice Theory as a Theory of Fundamental Rights}

Abstract

The article will make an analysis on Rawls' theory of justice as a theory of fundamental rights. The goal is to demonstrate that the notion of justice basic's principles and primary goods is a form of protection of fundamental rights, especially the right to freedom and equality. The research methodology is bibliographic. At the end, the proposal is made that fundamental rights are the criterion of justice to Rawls and, therefore, there will be the foundation of the constitutional text it'self, and also serve as a extra-positive justification of hypothetical fundamental norm. The justice means the respect to basics fundamental rights.

Keywords: Rawls. Justice. Fundamental rights. 


\section{Sumário}

1 Introdução. 2 A ideia de Justiça. 3 A teoria da Justiça de Rawls. 3.1 A posição original. 3.2 0s princípios da Justiça de Rawls. 3.3 Os bens primários. 4 Os direitos fundamentais. 5 0s direitos fundamentais na teoria da Justiça de Rawls. 6 Conclusão. 7 Referências. 


\section{INTRODUÇÃO}

John Rawls desenvolveu e aprimorou ao longo da sua notável carreira de jurista e filósofo uma célebre teoria da Justiça que superou fronteiras, línguas, além de despertar o interesse de críticos e admiradores ao redor do mundo. Daí, já se pode antever a relevância do presente estudo, menos pelas ideias que aqui serão lançadas e mais pela genialidade do autor que inspira e empresta o seu nome ao título do artigo.

O trabalho que ora se apresenta, contudo, não se trata de um fichamento ou mera repetição do pensamento de Rawls, em que pese a essencialidade de se descrever os conceitos básicos de sua teoria sobre a Justiça ao longo das linhas a seguir. Com efeito, buscar-se-á, a partir das concepções da teoria de Rawls, demonstrar que o seu estudo é a base de uma teoria dos direitos fundamentais.

Assim, as questões de método, tal como a concepção da posição original e do véu da ignorância; e de substância, tais como os conceitos de princípios básicos de Justiça e de bens primários desenvolvidos por Rawls, serão vistos como uma reafirmação de uma teoria dos direitos fundamentais. Nessa perspectiva, a origem de tais direitos também será objeto de estudo, notadamente para se demonstrar a dependência da teoria de Rawls dos direitos fundamentais.

Em outros termos, será defendido que, sem a ideia de direitos fundamentais, Rawls não teria suporte para sustentar a sua teoria da Justiça, sendo esta um singular instrumento de proteção daqueles direitos. Dessa forma, será feito um breve estudo sobre a ideia de Justiça, seguindo-se a apresentação de um esboço da teoria de Rawls. Posteriormente serão abordados os direitos fundamentais para, finalmente, ser feita a análise crítica sobre os temas anteriores a demonstrar suas indissociáveis interseções. 


\section{A IDEIA DE JUSTIÇA}

A Justiça é um termo relativo e demanda uma análise profunda para ser definida. Realmente, pode ser encarada como um valor a ser perseguido, como o ato de concretizar esse valor e, inclusive, pode ser uma ideia flexível a depender de alguma concepção preestabelecida. Conforme Reale (2002, p. 272):

A Justiça, como se vê, não é senão a expressão unitária e integrante dos valores todos de convivência, pressupõe o valor transcendental da pessoa humana, e representa, por sua vez, o pressuposto de toda ordem jurídica. Essa compreensão histórico-social da Justiça leva-nos a identificá-la como bem comum, dando, porém, a este termo sentido diverso do que lhe conferem os que atentam mais para os elementos de "estrutura", de forma abstrata e estática, sem reconhecerem que o bem comum só pode ser concebido, concretamente, como um processo incessante de composição de valorações e de interesses, tendo como base ou fulcro o valor condicionante da liberdade espiritual, a pessoa como fonte constitutiva da experiência ético-jurídica (grifos no original).

É de ver, no entanto, que a ideia de Justiça trata-se de algo que se demonstra caso a caso, a partir de uma conceituação geral. Ao consagrar a fórmula geral greco-romana, escreve Nader (2000, p. 101):

Com base nas concepções de Platão e de Aristóteles, o jurisconsulto Ulpiano assim a formulou: Justitia est constans et perpetua voluntas jus suum cuique tribuendi (Justiça é a constante e firme vontade de dar a cada um o que é seu). (...) a presente definição, além de retratar a Justiça como virtude humana, apresenta a idéia nuclear desse valor: Dar a cada um o que é seu. Esta colocação, que enganadamente alguns consideram ultrapassada em face da Justiça social, é verdadeira e definitiva; válida para todas as épocas e lugares, por ser uma definição apenas de natureza formal, que não define o conteúdo do seu de cada pessoa (grifos no original). 
Realmente, tarefa árdua é conceituar o que é justo, haja vista que se trata de um adjetivo afeito á severa carga pessoal de quem venha a estabelecer a definição, sendo a ambição de conceber um parâmetro objetivo um dos méritos da teoria de Rawls, como se verá. É possível, todavia, num linguajar mais vulgar, afirmar que é justo aquilo que está adequado, ou o que simplesmente se ajusta a uma determinada situação. Como se vê, a Justiça pode ser valor, ou virtude, mas ao mesmo tempo tem o aspecto de ato, precisamente o ato de dar a cada um o que é seu, sendo certo que se trata da principal finalidade do Direito. De acordo com Moncada (1995, v. 2, p. 43):

A “justiça” é a ordem ideal, a ordem perfeita. Já nos antigos, desde Pitágoras, pensavam assim. Justiça, segundo a idéia, é o mesmo que proporção e portanto igualdade. O símbolo mais perfeito desta igualdade era para aquele filósofo a figura geométrica do quadrado. Por certo, nem toda ordem é justa. Concebe-se a possibilidade de uma ordem menos justa. Mas será, por definição, justa toda a ordem que consistir na igual atribuição a cada um (já no seu ter, já no seu fazer) daquilo que especificadamente lhe couber ter ou fazer, qualquer que seja aliás o critério, em concreto, para tal atribuição feita. A nota peculiar do justo, dentro do conceito mais geral de “ordem", será pois assim, antes de tudo mais, a que já se achava admiravelmente expressa naquelas clássicas definições que os gregos nos davam da Justiça, ao reduzirem esta, ou a um simples suum cuique tribuere (Aristóteles), ou a um simples suum agere (Platão). Se a cada qual for lhe dado o que seu é, ou se cada qual fizer aquilo que lhe compete fazer dentro do todo de que faz parte, aí teremos, com efeito, realizada a mais completa Justiça segundo a idéia, abstraindo do seu conteúdo axiológico, quer se trate das partes dum organismo, quer dos homens na vida social.

Por sua vez, sob a perspectiva da Justiça como ato, escreve Telles Jr. (2002, p. 355) que: “Justiça é a RETRIBUIÇÃO AO QUE FOI DADO OU FEITO. Notemos que a Justiça não está somente na equivalência. 
Embora não existe Justiça sem equivalência, a Justiça está, propriamente, num ato: no ato de fazer algo equivalente ao que foi dado ou feito" (Caixa alta no original).

A despeito da fórmula ulpiânica de dar a cada um o que é seu, vê-se que não é possível estudar a Justiça sem a análise de um caso concreto, ou de um parâmetro para determinar exatamente a medida do que cabe a cada um. De fato, a herança de um pai deve ser dirigida aos seus herdeiros, ou deveria caber a quem mais cuidou do pai em vida? Em determinadas culturas deveria ser dirigida ao filho primogênito, conquanto os outros filhos fossem mais amorosos e mais amados. Da mesma forma, em determinados contextos não poderia existir nada mais justo do que o pai escolher o noivo de sua filha.

Como é intuitivo, aquilo que é justo pode ser extremamente injusto, a depender de outro ponto de vista, todavia, é de ver que está ínsita no ser humano a virtude da Justiça como um verdadeiro sentimento inerente ao espírito. Não é improvável que uma criança ainda sem discernimento formado não sinta o erro de se comportar igualmente a outra - um amiguinho, um irmão - e não ser agraciada com o mesmo presente, doce ou outro mimo qualquer. $\mathrm{O}$ modo de reação pode variar, com inconformismo ou resignação, mas até nas mentes em processo de formação a ideia do justo e do injusto travam inevitável embate.

É patente a problemática: por um lado, é bastante difícil traçar um parâmetro de Justiça que não signifique uma imposição subjetiva do seu idealizador; noutro sentido, é inerente à natureza humana a vontade de fazer o que é justo e de reprovar o que é injusto, partindo-se de uma concepção moral de ética mínima. A intuição faz crer que deve existir um ideal de equilíbrio para que se possa determinar de maneira objetiva o que é justo.

Já se pode pressentir que uma ideia equilibrada de Justiça pressupõe e por isso anda ladeada por dois elementos básicos: a liberdade e a igualdade. Como facilmente se constata, a liberdade e a igualdade podem 
ser consideradas os dois direitos fundamentais matrizes, daí, já se percebe que uma teoria de Justiça equilibrada está influenciada por tais direitos, haja vista a reverência que se presta a eles numa sociedade democrática. Nesse momento, insta pontuar que a Justiça é um feixe de valor, ato e finalidade intrínseco à natureza humana individual e social, voltado a manter o equilíbrio e a ordem nas relações, dando a cada um o que lhe cabe.

Nesse passo, caberia ao Direito, a começar pelo Direito Constitucional, indicar as diretrizes do que cabe a cada um, conforme as suas oportunidades e os seus méritos. Essa discussão de parâmetros, porém, vai além da ideia de Justiça e passa a ser de concreção da política social. À teoria da Justiça cumpre criar o ambiente propício para o desenvolvimento prático de dar a cada um o que é seu, inclusive de criar a própria constituição estatal como se a teoria do justo fosse um manual de instruções ao poder constituinte originário. Esse desafio foi enfrentado por John Rawls, que traçou uma teoria metódica e substancial de garantir a Justiça no Estado democrático, consoante será demonstrado nas linhas que se seguem.

\section{A TEORIA DA JUSTIÇA DE RAWLS}

O objetivo deste item é dar uma dimensão mínima dos principais elementos fomentadores da teoria da Justiça formulada por John Rawls. Serão apresentadas as ideias centrais de como o Estado democrático deve agir para que nele esteja presente a Justiça. A intenção é demonstrar que, de acordo com as premissas de Justiça inspiradas por Ralws, estar-se-á, em verdade - ou, melhor se expressando, conjuntamente - formulando uma teoria de proteção dos direitos fundamentais.

Sem dúvida, um dos méritos da teoria da Justiça idealizada por Rawls diz respeito a sua tentativa de criar um método objetivo de se determinar o que é justo. De fato, como exposto noutro momento, não é fácil determinar a medida de dar a cada um o que seu, quando as pessoas 
sempre podem estar influenciadas pelos mais diversos fatores, tais como políticos, religiosos, ideológicos, etc., sendo a construção da metódica de Rawls uma objetivação de todas as premissas influenciadoras.

Realmente, numa sociedade de fundamentação religiosa, os critérios de intervenção do Estado, notadamente na definição do que é justo, podem ser objetivos, mas coerentes com o fundamentalismo, de sorte que é possível agir com neutralidade sem qualquer interferência do pensamento pessoal de quem manda apedrejar uma mulher adúltera. Sucede que na formulação de Rawls, até o parâmetro de Justiça - que no exemplo citado seria a fundamentação religiosa - será objetivado, de modo a ficar alheio a determinados seguimentos ideológicos. Não se trata, porém, somente de método, pois o teórico da Justiça também aponta elementos substanciais para completar a sua fórmula, notadamente porque a supõe como uma equidade liberal. Escreve Siqueira (2011, p. 272):

A Teoria da Justiça apresenta como propósito a fixação dos princípios de Justiça basilares às instituições de uma sociedade democrática. Para alcançar este objetivo, John Rawls não apenas elabora uma teoria processual - tratando do procedimento no qual são fixados os princípios de Justiça - como efetua uma análise substancial do problema, fixando o conteúdo dos princípios de Justiça.

A teoria da Justiça concebida por Rawls é um processo e, como tal, possui suas fases. Nas linhas a seguir será feita uma breve análise propedêutica sobre as ditas fases do processo rawlsiano.

\subsection{A posição original}

A teoria da Justiça de Rawls é contratualista, na medida em que os parâmetros de Justiça hão de ser estabelecidos a partir de um acordo de vontades entre os membros da sociedade que se comprometem a estabelecer os princípios básicos aos quais vão se submeter de modo cooperado. 
Tem-se, assim, a premissa de que a ideia de formação do Estado concebida por Hobbes, Locke e Rousseau, a partir de um contrato social para justificar o poder do ente político, cada um com as suas nuances, foi o ponto inicial da teoria da Justiça nesse momento estudada.

Dessa forma, Rawls imagina - talvez como Kelsen imaginou a norma hipotética fundamental com evidente inspiração metafísica - um momento no qual os membros de um Estado que quer se dizer democrático vão traçar o plano dos valores da sociedade a partir da ideia de Justiça. É de se observar que esse momento inicial seria anterior inclusive à ideia de poder constituinte originário, sendo este um efeito consequente daquele instante de antecedência necessária.

Resta evidente, porém, que tudo tem o seu início. O fato de Rawls imaginar um momento genético solene para o início de uma sociedade que almeja a Justiça não é nada demais. Com efeito, todo empreendimento exige um marco primeiro de planejamento, inclusive para a prática de atividades criminosas, por exemplo. O mérito do gênio de Rawls consiste em teorizar um modo de agir especial dos membros da sociedade nesse momento inicial, uma postura essencial para que se consiga estabelecer os princípios de Justiça. Noutras palavras, Rawls concebe uma posição original dos "contratantes" da avença social, indispensável para que frutifiquem daí elementos de Justiça puros, no sentido de serem despidos de quaisquer interesses, paixões, fraquezas, enfim, despojados de qualquer influência subjetiva preconcebida dos agentes estabelecedores dos princípios de Justiça.

Nesse contexto, para se chegar aos que seriam os verdadeiros princípios de Justiça, os participantes desse ato fundamentador devem desconhecer, ou tentar abstrair tudo que possa influenciá-los, de modo que não poderiam saber o que lhes traria vantagens ou prejuízos, a agir de modo essencialmente neutro. Seria necessário vestir um "véu da ignorância” momentâneo para garantir uma espécie de pureza do instante, 
especificamente no sentido de retirar influências ideológicas do ato que deve resguardar, com equidade, os anseios mínimos de todos, de modo independente do credo, cultura, origem ou qualquer outro fator de diferenciação. Observa Siqueira (2011, p. 86):

O primeiro passo, portanto, da Teoria de Justiça consubstancia-se na elaboração do procedimento adequado à fixação do conteúdo dos princípios de Justiça. Neste contexto, John Rawls conceitua a posição original como o primeiro acordo ideal entre os representantes da sociedade que, concebendo a todos como pessoas livres e iguais, deliberariam acerca dos princípios de Justiça basilares às instituições sociais sob o véu da ignorância, ou seja, sem conhecimento dos interesses seus e das pessoas a que representam (grifos no original).

Para seguir esse padrão, os parceiros da posição original devem agir de acordo com a moral ética uns perante os outros, conforme os ditames daquilo que é razoável e racional. Não se pode olvidar que a pretensão do teórico da Justiça é estabelecer uma sociedade democrática conforme a equidade. Nessa situação, parte-se de uma posição original na qual os parceiros devem vestir um véu que os priva das precompreensões para que não sejam influenciados por nenhum interesse menor e agir de modo razoável e racional. Como já foi referido noutra ocasião, o instante da posição original deve anteceder inclusive a ideia do Poder Constituinte originário, que não obstante ser entendido pela doutrina constitucional como soberano e ilimitado, na teoria da Justiça de Rawls deve se subordinar ao acordo dos parceiros da posição original. Para Rawls (2000, p. 194):

Desse modo, os parceiros da posição original são indivíduos representativos racionalmente autônomos, limitados pelos cerceamentos razoáveis que comportam a posição original, e sua tarefa consiste em adotar princípios de Justiça que se apliquem à estrutura básica. Já os delegados de uma assembléia constituinte têm menos margem de liberdade, uma vez que devem aplicar, quando da escolha de uma constituição, os princípios de Justiça que foram adotados na posição original. Os legis- 
ladores, numa assembléia parlamentar, têm ainda menos liberdade, pois as leis que devem promulgar, quaisquer que sejam elas, devem estar de acordo, ao mesmo tempo, com a constituição e com os dois princípios de Justiça. À medida que se desenrolam as etapas e se dá a transformação das tarefas requeridas que se tornam cada vez mais precisas, os cerceamentos do Razoável se fazem mais pesados e o véu da ignorância se torna menos espesso.

A teoria da Justiça de Rawls começa com um procedimento que, segundo o idealizador, redundará nos dois princípios da Justiça basilares do Estado Democrático de Direito como equidade. Dessa maneira, a substância da teoria da Justiça seria uma consequência necessária do procedimento inicial adotado. $\mathrm{O}$ mais interessante diz respeito ao fato de esses princípios estamparem a base dos direitos fundamentais em momento anterior à ideia de constituição. Quais seriam, então, tais princípios?

\subsection{Os princípios da Justiça de Rawls}

Os princípios da Justiça formulados por John Rawls simplesmente consagram os dois direitos fundamentais básicos, quais sejam, a liberdade e a igualdade nas variadas vertentes em que podem ser aplicados. A liberdade não se resume à ideia de ir e vir, mas inclui, entre outras acepções, a liberdade de pensamento e de expressão; e a igualdade é muito mais do que se impor um tratamento igual, deve também assegurar oportunidades e diminuir as inevitáveis diferenças injustificadas.

Assim, dois são os princípios básicos de Justiça. Primeiramente, existiria um direito igual de liberdade para todos e; em segundo lugar, as diferenças são admitidas, mas desde que exista acesso às posições da sociedade para qualquer de seus membros, conferindo-se oportunidades equitativas e para se promover um maior benefício para os menos favorecidos. Escreve Rawls (2007a, p. 112): 
Enunciarei agora e explicarei os dois princípios de Justiça, e discutirei, em seguida, a pertinência desses princípios para uma sociedade bem-ordenada. Eles rezam como se segue: 1 . Cada pessoa tem um direito igual ao mais extensivo esquema de liberdades fundamentais iguais compativeis com um esquema semelhante de liberdades para todos. 2. As desigualdades sociais e econômicas devem satisfazer duas condições: elas devem ser (a) para o maior benefício esperado dos menos favorecidos; e (b) vinculadas a cargos e posições abertas a todos em condições de oportunidade equitativa. $\mathrm{O}$ primeiro desses princípios deve ter prioridade sobre o segundo; e a medida de benefício para os menos favorecidos é especificada em termos de um índice de bens primários sociais.

Preciosas conclusões podem ser extraídas das fórmulas principiológicas de Rawls. Logo se vê que a ideia de Justiça do teórico é liberal, porquanto confessa a prioridade que se deve dar às liberdades, notadamente para se alçar os postos de relevância sociais que a todos devem estar abertos. Ao mesmo tempo, porém, quando se depara com as inevitáveis diferenças que existem no corpo social, Rawls afirma que elas devem contemplar o mérito assegurando-se as oportunidades e beneficiar os componentes das classes mais excluídas. Percebe-se que no pensamento sobre a Justiça também deve estar presente a ideia de solidariedade.

Ao formular os seus princípios básicos de Justiça tal como anteriormente descritos, Rawls ainda não chegou no momento constitucional. Nessa segunda fase da teoria da Justiça, os parceiros na posição original, alheios aos interesses menores por força do véu da ignorância, chegariam inevitavelmente a tais princípios, eis que eles permitiriam, notadamente por força da relevância das liberdades, a concreção de uma sociedade plural e tolerante com as variadas formas de segmentos do ser humano. Conforme Rawls (2007b, p. 47):

Passo agora a algumas observações sobre os princípios de uma constituição justa. Terei que pressupor aqui algumas teses acerca dos princípios de Justiça. Em particular, assumirei que haja dois princípios de 
Justiça que propriamente se aplicam à estrutura fundamental das instituições do sistema social e, portanto, à constituição. O primeiro destes princípios requer que todos tenham direito igual à mais ampla liberdade compatível com uma liberdade semelhante para todos; o segundo é que desigualdades são arbitrárias a menos que seja razoável ter a expectativa de que elas funcionarão para a vantagem de todos e contanto que as posições e cargos aos quais elas estão ligadas ou a partir dos quais elas podem ser obtidas são abertos a todos. Assumirei que estes sejam os princípios que podem ser derivados pela imposição de restrições morais a pessoas racionais e mutuamente auto-interessadas, uma vez que elas propõem demandas conflitantes acerca da forma básica de suas instituições comuns quando questões de Justiça têm lugar.

Ao assegurar as liberdades nas suas diversas nuances e ao lidar com as diferenças - o inverso da igualdade - no sentido de resguardar o mérito (acesso aos postos e funções com igual oportunidade) e os menos favorecidos, percebe-se a ambição de uma fórmula que seja aplicável para qualquer aglomerado humano pretendente a desenvolver um corpo social minimamente justo. Por óbvio, ao estabelecer os seus princípios básicos, o teórico da Justiça foi alvo de críticas, pois sempre seria possível agregar um ou outro elemento. Ao criticar Rawls por não contemplar nos seus princípios de Justiça as pessoas incapazes ou que padecem de necessidades especiais, escreve Sen (2009, p. 260-261):

In fact, Rawls does recommend special correctives for "special needs", such a disability ou and handicap, even though this is not a part of his principles of justice. These corrections come not in setting up "the basic institutional structure" of the society at the "constitutional satage", but as something that should emerge later on in the use of the institutions thus set up, particularly in the "legislative stage". This makes the reach of Rawls's motivation clear enough, and the question to be asked is whether this is adequate as a way of rectifying the partial blindness of the perspective of resources and primary goods in Rawlsian principles of justice. 
É de ver, no entanto, que a fórmula de Rawls destaca-se por permitir a inserção de outros valores nos seus princípios, mas em momento posterior, notadamente na fase constitucional ou legislativa da sociedade. Aí está um dos seus méritos, especificamente o de adaptação dos seus princípios nas diversas formas sociais por eles serem receptivos a processos de enriquecimento, com a base sempre constituindo os dois princípios de direito igual às liberdades e a diferença pelos postos e funções acessíveis a todos em vista das oportunidades e em benefício dos menos favorecidos.

De mais a mais, para Rawls desenvolver um processo de Justiça que se iniciaria a partir da posição original, de modo a posteriormente fincar dois princípios imbricados com os direitos fundamentais à liberdade e à igualdade, ele deveria imaginar alguma utilidade em benefício da sociedade para inspirar sua Filosofia. A finalidade desse processo parece ser resguardar certos tipos de bens essenciais paras as pessoas, os denominados bens primários de Rawls.

\subsection{Os bens primários}

Numa fase seguinte de sua teoria da Justiça, John Rawls elenca determinados bens primários sem os quais a sociedade não se desenvolveria e que seriam alcançados graças ao conteúdo dos seus princípios da Justiça que, por sua vez, puderam ser gerados devido ao véu da ignorância que vestiu os parceiros no momento da posição original, quando assumiram o dever de cooperação essencial ao ambiente de equidade.

Assim, o teórico da Justiça elenca cinco categorias de bens primários (Rawls, 2000, p. 166-167), são elas: as liberdades básicas, nas quais se incluem, entre outras, a liberdade de pensamento e a liberdade de consciência; a liberdade de movimento e a livre escolha de ocupação, a permitir a todos perseguir qualquer meta, bem como desistir, tentar de novo, mudar de ideia...; os poderes e as prerrogativas das funções e dos 
postos de responsabilidade; a renda e a riqueza e, por fim, as bases sociais do respeito próprio. Como os parceiros da posição original estariam indiferentes aos anseios da sociedade por eles representadas por força do véu da ignorância, seria necessário determinar os bens essenciais que atenderiam aos desejos de todos os atores sociais. Conforme Rawls (2000, p. 165):

Porém, aqui devo voltar-me para as considerações que fazem agir os parceiros na posição original. É claro que a sua meta de conjunto é assumir sua responsabilidade e fazer o melhor possível para avançar o bem determinado das pessoas que representam. O problema reside no seguinte: dadas as restrições impostas pelo véu da ignorância, pode parecer impossível que os parceiros estabeleçam o que é o bem para essas pessoas e que, portanto, produzam um acordo racional em seu nome. Para resolver esse problema, introduzimos a idéia de bens primários e enumeramos uma lista dos diversos elementos que entram sob essa designação. A idéia principal é a de que se distingam os bens primários dos outros procurando quais são os bens geralmente necessários como condições sociais e como meios polivalentes que permitam às pessoas buscar suas concepções determinadas do bem e desenvolver e exercer suas duas faculdades morais. Aqui, devemos interessar-nos pelas necessidades sociais e pelas circunstâncias normais da vida humana numa sociedade democrática.

Ao analisar os bens primários de Rawls constata-se que apenas os poderes e as prerrogativas dos postos de funções de responsabilidade não ostentam um nítido viés de direito fundamental, não obstante sua evidente importância político-institucional. No mais, entre os bens primários, dois consagram as liberdades; um encampa a renda e a riqueza, de modo que se a propriedade não faz parte dos princípios de Justiça de Rawls, sem dúvida pode ser extraída desse bem primário; e, finalmente, as bases sociais do respeito próprio detêm visível relação com a dignidade humana.

É possivel afirmar que a teoria da Justiça de Rawls, com outras complementações, possui um tripé essencial de sustentação formada pela ideia da posição original, dos princípios básicos de Justiça e dos bens primários. 
A formulação almeja servir de base para um Estado democrático, daquilo que melhor atenderia aos anseios gerais da sociedade plural, considerando as inevitáveis diferenças entre os seus membros. Deve se render homenagens à Filosofia rawlsiana, entretanto chama-se a atenção neste trabalho para o que diz respeito ao fato de a fórmula de Justiça encampada ostentar, em última análise, uma teoria dos direitos fundamentais como a base da ambiência social equitativa, o que impõe uma análise sobre esses direitos adjetivados como imprescindíveis.

\section{OS DIREITOS FUNDAMENTAIS}

Ao longo da História da humanidade, somente na parte final desse "livro inacabado" começou a se oficializar a ideia de que as pessoas, pelo simples fato de serem pessoas, deveriam ter assegurados certos direitos indispensáveis a uma vivência mínima, os quais hoje considerados fundamentais a uma vivência digna. Outrora vigorava a ideia de opressão das mais variadas e arcaicas concepções de poder político, que via no ser humano um mero objeto de exploração ou sujeição, quer pelo domínio militar, escravocrata, feudal, absolutista, tribal ou religioso.

A consagração de certos direitos tidos como fundamentais surge no final do século 18 da era cristã e que a todo instante são incrementados no decorrer da História até os dias atuais. O marco inicial é dividido entre a independência das 13 colônias inglesas dos Estados Unidos da América do Norte, juntamente com a Revolução Francesa, que iniciou a derrocada do absolutismo monárquico na Europa. Tal reviravolta mundial ocorreu em 1776 e em 1789, respectivamente, e coincide com a ideia de constitucionalismo, oportunidade na qual o poder, pelo domínio econômico burguês e sob os auspícios de ser entregue ao "povo", foi retirado dos monarcas para ser controlado de modo sub-reptício pelos detentores das riquezas 
por meio de um texto político constitucional. Como primeiro ato da nova ordem, era necessário estabelecer um rol de direitos essenciais de todos a serem protegidos pelo Estado. Expressa Sarlet (2009, p. 43):

A despeito do dissídio doutrinário sobre a paternidade dos direitos fundamentais, disputada entre a Declaração de Direitos do Povo da Virgínia, de 1776, e a Declaração Francesa, de 1789, é a primeira que marca a transição dos direitos de liberdade legais ingleses para os direitos fundamentais constitucionais. As declarações americanas incorporaram virtualmente os direitos e liberdades já reconhecidos pelas suas antecessoras inglesas do século XVII, direitos estes que também tinham sido reconhecidos aos súditos das colônias americanas, com a nota distintiva de que, a despeito da virtual identidade de conteúdo, guardaram as características de universalidade e supremacia dos direitos naturais, sendo-lhes reconhecida eficácia, inclusive em relação à representação popular, vinculando, assim, todos os poderes públicos. Com a nota distintiva da supremacia normativa e a posterior garantia de sua justiciabilidade por intermédio da Suprema Corte e do controle judicial da constitucionalidade, pela primeira vez os direitos naturais do homem foram acolhidos e positivados como direitos fundamentais constitucionais, ainda que este status constitucional da fundamentalidade em sentido formal tenha sido definitivamente consagrado somente a partir da incorporação de uma declaração de direitos à Constituição em 1791, mais exatamente, a partir do momento em que foi afirmada na prática da Suprema Corte a sua supremacia normativa.

A origem dos direitos fundamentais estaria no Direito Natural ou numa moral ética, como divide a doutrina, mas o que importa frisar é que tais direitos são os considerados mínimos, normalmente incorporados aos textos constitucionais de Estados democráticos ou não. Como exemplo de catálogo de direitos fundamentais inserto em Constituição outorgada, tem-se a Carta Imperial pátria de 1824 . Sobre a fundamentação dos direitos humanos e reconhecendo que tal debate se encontra em aberto, escreve Silva (2007, p. 204): 
A fundamentação jusnaturalista identifica-se com os pressupostos do Direito Natural, reconhecendo a existência de uma ordem prévia de direitos naturais, inerente à condição humana. 7. A fundamentação ética dos direitos humanos identifica-se com os valores e exigências éticas que respaldam esses direitos e são o conteúdo dessa fundamentação, remetendo-se à idéia de dignidade humana. 8. A questão da justificação racional dos direitos humanos ainda se encontra aberta, não se podendo dizer que há uma uniformidade de pensamento nesse particular, nem perspectivas de consenso.

Tais direitos surgem ao longo da evolução da sociedade, daí se falar em gerações de direitos, na medida do momento histórico de surgimento que, coincidentemente, seguem o lema da Revolução Francesa, conforme constatou Karel Vazak na célebre conferência de Estrasburgo. De início foram assegurados os direitos de liberdade em relação ao Estado, as chamadas liberdades negativas repudiando a intervenção do Estado na vida das pessoas; posteriormente, os direitos à igualdade material e, por fim, os diretos de fraternidade. Parte da doutrina (Bonavides, 2009) vislumbra uma quarta e quinta geração (ou dimensão) dos direitos fundamentais, nas quais estariam incluídos os direitos à democracia, à informação, ao pluralismo e à paz, todavia não há aceitação pacífica sobre o tema.

Os direitos fundamentais são dotados, todos eles, de notável carga valorativa, daí a proteção especial que recebem no âmbito internacional sobre a roupagem de direitos humanos e no âmbito interno dos Estados como cláusulas pétreas. Vários bens jurídicos podem ser objeto da proteção normativa dos direitos fundamentais, como a propriedade e a intimidade, por exemplo. O rol de tais direitos trata-se, em verdade, de uma lista aberta de bens jurídicos que serão, de certo modo, relativos à cultura e à história de determinada sociedade, no entanto a liberdade, a igualdade e a dignidade são elementos universais. Conforme Lopes (2001, p. 73): 
A respeito de uma ordem hierárquica, questiona-se sobre os critérios utilizados na escolha dos valores que farão parte da lista e sobre os critérios utilizados para estabelecer a ordem, isto é, se será uma lista completa e fechada ou aberta. Na verdade, só se poderia obter uma lista fechada através de um elenco de valores de alto grau de generalidade, como dignidade, liberdade, igualdade; mesmo assim, muitos valores seriam excluídos. De qualquer maneira, percebe-se que é impossível formular um catálogo completo de valores, o que dificulta qualquer tentativa de criar uma ordem hierárquica de algo que está incompleto.

Inclusive nas sociedades fundamentalistas, nas quais esses direitos não são respeitados, ainda assim serão caros ao corpo social e só não são devidamente efetivados em virtude da opressão da força estatal controlada por algum estamento dominante ditatorial contrário à ideia de bem comum.

A abertura do rol dos direitos fundamentais à medida que permite $\mathrm{a}$ evolução da sociedade para incorporar no seu modelo jurídico novos valores tidos como essenciais, traz o problema de permitir uma banalização do termo, uma vez que que várias correntes sociais procuram inserir nesse status os direitos dos seus respectivos interesses, no evidente intuito de blindarem suas aspirações da mutação constitucional ou de interferências legislativas, haja vista que, como fundamental, o Direito em si seria uma cláusula pétrea. Por tal razão fala-se em direito fundamental ao período de férias de 30 dias; no direito fundamental de uma entidade religiosa ter seu patrimônio imune à tributação, entre outros tantos direitos constitucionais que, em que pesem não estarem inseridos no catálogo de direitos e garantias individuais, são defendidos como se assim fossem pelas pessoas ou entidades que deles gozam.

É de ver que a própria Constituição Federal de 1988 não cerra o seu catálogo de direitos fundamentais, pois o artigo $5^{\circ}$, $\S 2^{\circ}$ prevê uma cláusula de abertura, como não poderia deixar de ser, exatamente para permitir o progresso jurídico fundamental. O que se critica é o uso abusivo da 
cláusula de abertura dos direitos fundamentais para nele se incluir todos os interesses, pois se trata de uma valorização indevida de um direito que não é fundamental, com a consequente desvalorização mais indevida ainda dos direitos que efetivamente são fundamentais. Com a desculpa da interpretação dos princípios, o Judiciário acaba por criar um Direito paralelo em prejuízo da segurança jurídica e do poder Legislativo. De acordo com Rodrigues Júnior (2010, p. 39):

Há ainda o problema da "principiolatria” e a proliferação de princípios, como tem denunciado Lenio Luiz Streck como o fenômeno do "panprincipiologismo", de molde a facilitar o abandono de certos parâmetros de segurança e de certeza jurídica por uma discricionariedade judicial abusiva.

Assim, urge que se delimite uma matriz dos valores protegidos pelos direitos fundamentais, notadamente para se resguardar tais direitos de uma miscigenação impura com outros direitos que não guardam o mesmo grau de relevância, ainda que também sejam oriundos de um texto constitucional. Parece que a resposta sobre tal matriz estaria na própria história e nas gerações dos direitos fundamentais, como bem delimitado no lema da Revolução Francesa pela liberdade, igualdade e fraternidade; e que, de igual modo, podem ser extraídos dos princípios básicos de Justiça de Rawls.

\section{OS DIREITOS FUNDAMENTAIS NA TEORIA DA JUSTIÇA DE RAWLS}

Como já foi mencionado em outro momento, na teoria da Justiça de Rawls foram delimitados dois princípios básicos, quais sejam: o direito igual de liberdade para todos e, em segundo lugar, as diferenças são admitidas, mas desde que exista acesso às posições da sociedade para qualquer de seus membros, conferindo-se oportunidades equitativas e para promover um maior beneficio para os menos favorecidos. 
Dos princípios básicos extrai-se a matriz dos direitos fundamentais, senão vejamos: ao se falar em direito igual de liberdade para todos, numa só expressão estão assegurados os valores fundamentais da liberdade e da igualdade; outrossim, quando Rawls trata das diferenças, prescreve acesso a todos no que tange às oportunidades e também em benefício dos menos favorecidos, o que denota a submissão à fraternidade social. Da mesma forma, foi frisado que a teoria da Justiça de Rawls antecede o texto constitucional, que deverá ser elaborado visando a atender aos princípios básicos anteriormente formulados.

De mais a mais, não se pode olvidar que a formulação de Rawls tem em mira um Estado Democrático de Direito e parâmetros de equidade. A partir da submissão à liberdade e à igualdade tal como estabelecida na teoria da Justiça, estar-se-á fomentando uma sociedade democrática e justa. Em nítida concordância do vínculo essencial entre os direitos fundamentais com a Justiça e o próprio Estado democrático, escreve Sarlet (2009, p. 62):

Com base nas idéias aqui apenas pontualmente lançadas e sumariamente desenvolvidas, há como sustentar que, além da íntima vinculação entre as noções de Estado de Direito, Constituição e direitos fundamentais, estes, sob o aspecto de concretizações do princípio da dignidade humana, bem como dos valores da igualdade, liberdade e Justiça, constituem condição de existência e medida da legitimidade de um autêntico Estado Democrático e Social de Direito, tal qual como consagrado também em nosso direito constitucional positivo vigente.

É possível, então, entender que os direitos fundamentais à liberdade, à igualdade e à fraternidade, não obstante estarem previstos no corpo normativo de uma Constituição democrática, são, precisamente, o fundamento da própria Constituição. É possível afirmar que a teoria da Justiça de Rawls seria, na verdade, a norma hipotética fundamental idea- 
lizada por Hans Kelsen no sentido de ser o cume da pirâmide normativa e base de justificação da constituição estatal. Sobre a norma fundamental hipotética de Kelsen, adverte Vasconcelos (2010, p. 187-188):

A multiplicidade de funções da NFH dá bem a medida de sua importância para a Teoria Pura do Direito. Com o objetivo de precisão, procuremos adotar, ao determiná-las, as próprias palavras de Kelsen. Veremos que, relativamente a cada ordem jurídica, a norma básica desempenha as seguintes funções: $1^{\mathrm{a}}$ - dar-lhe fundamento de validade; [...] $2^{\mathrm{a}}-$ garantir-lhe a unidade; [...] $3^{\text {a }}$ - conferir competência para criação de Direito; [...] $4^{\mathrm{a}}$ - transmitir juridicidade aos atos da conduta humana; $5^{\text {a }}$ - possibilitar a existência da ciência do Direito e da interpretação jurídica; [...] $6^{\text {a }}$ - permitir a formulação de juízos de valor jurídico; $7^{\mathrm{a}}$ - propiciar condições para o conhecimento do Direito positivo [...].

Em outras palavras, os princípios básicos de Justiça da teoria de Rawls ostentam valores que, uma vez normatizados, são direitos fundamentais, especificamente os direitos fundamentais matrizes da liberdade e da igualdade. Ora, a considerar que as ideias da posição original e da formulação dos princípios básicos antecedem o poder constituinte originário, então pode-se concluir que a própria atuação do poder criador da Constituição é limitada e subordinada à ideia dos direitos fundamentais, caso pretenda estabelecer um Estado democrático.

É possível inclusive deduzir que John Rawls respondeu à crítica mais contundente que recaiu sobre a Teoria Pura do Direito de Hans Kelsen quando este fundamentou toda a ordem jurídica a partir de uma norma fundamental hipotética e da qual surgiria a Constituição. Realmente, não seria um direito pressuposto e hipotético que fundamentaria o texto constitucional, mas princípios básicos, tal como intuídos por Rawls, que trazem em si os valores essenciais dos direitos fundamentais, quais sejam, a liberdade e a igualdade. Dessa forma, quando um texto constitucional consagra esses direitos num rol de direitos fundamentais, o constituinte não os criou ou os estabeleceu, mas simplesmente os declarou, na 
medida em que eles seriam o fundamento do próprio poder constituinte originário. Em síntese, a norma fundamental hipotética seria os princípios de Justiça de Rawls. O mais paradoxal dessa conclusão é que os direitos fundamentais possuem a sua origem no Direito Natural ou numa moral ética. Então, essa seria a origem da teoria de Kelsen, que se diz pura, mas somente seria pura da Constituição para baixo, pois na tese aqui defendida, a norma hipotética fundamental, por comportar os princípios da Justiça de Rawls, possui inegável carga valorativa suprapositiva.

Por fim, cabe ressaltar que o teórico da Justiça confere prioridade à liberdade, pois por ela passaria a proteção dos outros direitos. Importa destacar, porém, que não deve se tratar de uma liberdade liberal, tal como concebida pela noção individualista do ser, em que seria cada um por si, mas, na verdade, uma liberdade libertária. De acordo com Bobbio (1996, p. 72):

A liberdade na tradição liberal é individualista e encontra a sua plena realização na redução a termos mínimos do poder coletivo, personificado historicamente pelo Estado; a liberdade da tradição libertária é comunitária e se realiza plenamente apenas na máxima distribuição do poder social, de modo a que todos participem dele em igual medida. A sociedade ideal dos primeiros é uma comunidade de indivíduos livres; a dos segundos é uma comunidade livre de indivíduos associados.

Ao se realçar a liberdade e a igualdade como direitos fundamentais matrizes, não é uma diminuição em relação a tais direitos da vida e da dignidade. Estes últimos são verdadeiros atributos da entidade humana, de sorte que seriam condições sem as quais não se poderia falar em liberdade ou em igualdade. As pessoas devem ser livres para serem felizes em sociedade, pois como ser político, o ser humano precisa do seu semelhante para viver, e não pode ser admitida a opressão entre os semelhantes, pois significaria ofensa à liberdade e à igualdade. 


\section{CONCLUSÃO}

A teoria da Justiça desenvolvida por John Rawls, especialmente por força dos princípios de Justiça por ela adotados, trata-se, também, de uma teoria dos direitos fundamentais, haja vista que a construção intelectual é voltada a assegurar determinadas premissas. Observa-se especial destaque para os valores da liberdade e da igualdade, que são, indubitavelmente, os direitos fundamentais matrizes.

Assim, a Justiça para a teoria de Rawls poderia ser confundida com o resguardo dos direitos fundamentais, principalmente o direito à liberdade. Ao admitir-se também a compreensão de que a construção de tal teoria antecede, inclusive, a fase constitucional, é possível concluir que os direitos fundamentais também seriam condicionantes do poder constituinte originário.

Evidente que o Estado Democrático de Direito é o parâmetro do desenvolvimento de Rawls, mas é certo que esta ideia de Estado tende a se universalizar com o progresso humano e intelectual das civilizações, haja vista que se trata do modelo de ordem jurídica que assegura os direitos fundamentais.

A antiga fórmula de dar a cada um o que é seu, sem causar prejuízo a outrem, pode ser entendida, com inspiração da teoria da Justiça de Rawls, no sentido de se respeitar os direitos fundamentais de todos. Ser justo é observar os direitos essenciais, pois, em última análise, os princípios básicos de Justiça e os bens primários terão por objeto o respeito aos valores jurídicos fundamentais.

\section{REFERÊNCIAS}

BOBBIO, Norberto. Igualdade e liberdade. Tradução Carlos Nelson Coutinho. Rio de Janeiro: Ediouro, 1996. 
BONAVIDES, Paulo. Curso de direito constitucional. 24. ed. São Paulo: Malheiros, 2009.

BRASIL. Constituição da República Federativa do Brasil. Brasília, DF: Senado Federal, 1988.

. Constituição Política do Império do Brazil (de 25 de março de 1824).

LOPES, Ana Maria D’Ávila. Os direitos fundamentais como limites ao poder de legislar. Porto Alegre: Sergio Antonio Fabris Editor, 2001.

MONCADA, Luís Cabral de. Filosofia do direito e do estado. Coimbra: Coimbra Editora, 1995. V. 2.

NADER, Paulo. Introdução ao estudo do direito. 20. ed. Rio de Janeiro: Forense, 2000.

RAWLS, John. Justiça e democracia. Tradução Irene A. Paternot. São Paulo: Martins Fontes, 2000.

. Obrigação jurídica e o dever de agir com equidade (fair play). Tradução Wladimir Barreto Lisboa. Revista Estudos Jurídicos. São Leopoldo: Unisinos, v. 40, n. 1, p. 44-49, jan./jun. 2007b.

. Uma concepção kantiana de igualdade. Tradução Nythamar de Oliveira. Revista Veritas, Porto Alegre: PUCRS, v. 52, n. 1, p. 108-119, mar. 2007a. REALE, Miguel. Filosofia do direito. 20. ed. São Paulo: Saraiva, 2002.

RODRIGUES JÚNIOR, Otávio Luiz. Estatuto epistemológico do direito civil contemporâneo na tradição de civil law em face do neoconstitucionalismo e dos princípios. Revista Meritum. v. 5, n. 2, p. 13-52, Belo-Horizonte: Universidade Fumec, jul./dez. 2010.

SARLET, Ingo Wolfgang. A eficácia dos direitos fundamentais: uma teoria geral dos direitos fundamentais na perspectiva constitucional. 10. ed. Porto Alegre: Livraria do Advogado, 2009.

SEN, Amartya. The idea of justice. 1. ed. Cambridge: Harvard University Press, 2009 . 
SILVA, Fernanda Duarte Lopes Lucas da. Fundamentando os direitos humanos: um breve inventário. In: TORRES, Ricardo Lobo (Org.). Legitimação dos direitos humanos. Rio de Janeiro: Renovar, 2007.

SIQUEIRA, Natércia Sampaio. Tributação e neutralidade no estado democrático de direito. Fortaleza, Unifor, 2011. 272p. Tese (Doutorado em Direito) - Programa de Pós-Graduação em Direito, Universidade de Fortaleza, 2011. TELLES JÚNIOR, Goffredo. Iniciação na ciência do direito. 2. ed. São Paulo: Saraiva, 2002.

VASCONCELOS, Arnaldo. Teoria pura do direito: repasse crítico dos seus principais fundamentos. 2. ed. Rio de Janeiro: GZ, 2010.

Recebido em: 10/4/2014

Aceito em: $11 / 8 / 2014$ 